\title{
Aza-bicycles Synthesis Through Formal Aza [3+3], [3+2+1] and [3+1+1+1] Cycloadditions Between Enaminones, Aldehydes and Meldrum's Acid Derivatives.
}

\section{Lourenço Luis Botelho de Santana*, Silvio Cunha}

\begin{abstract}
Universidade Federal da Bahia, Instituto de Química Campus de Ondina - 40.170-290 - Salvador - BA, Brasil INCT de Energia e Ambiente, Universidade Federal da Bahia, Campus de Ondina, Salvador - BA, 40170-290 *botelhofar@hotmail.com
\end{abstract}

Keywords:Yonemitsu reaction, aza-annulation, multicomponent reaction

\section{INTRODUCTION}

Aza-bicycles are an important scafold because a great number of biological active alkaloids and synthetic analogous belong to this class. ${ }^{1}$ Employing enaminones in order to obtain these compounds is strategic, once enaminones are obtained in good yields and can be used to prepare diverse heterocycles. This work evaluates the bicomponent aza-annulation [3+3] reaction between enaminones and Meldrum's acid derivatives, as well as the trimolecular $[3+2+1]$ and the tetramolecular $[3+1+1+1]$ multicomponent reactions. ${ }^{2,3}$

\section{RESULTS AND DISCUSSION}

The aza-annulation [3+3] reaction with previously synthesized Meldrum's acid alkilidenes ${ }^{4,5}$ and cyclic enaminone 4 led to several indolizidinones.

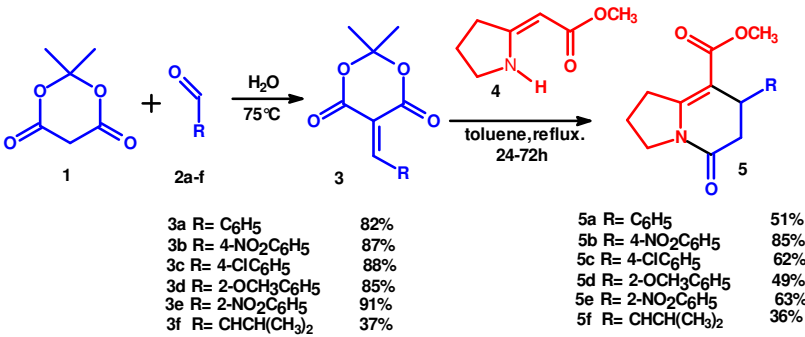

\section{Scheme 1.}

This kind of nucleous can also be accessed by a tricomponent $[3+2+1]$ reaction, although with low yields, as shown on scheme 2 .

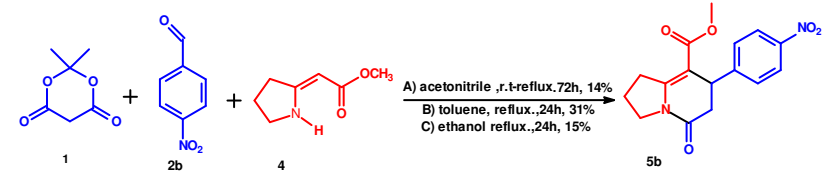

Scheme 2.

When the reaction was performed in ethanol, at room temperature, a tetramolecular $[3+1+1+1]$ azaannulation reaction occurred, leading to spyrocompounds $\mathbf{6 a - I}$, following according to a Yonemitsu-like condensation and a single diastereomer was formed,scheme 3.

Presuming that Knoevenagel adducts are involved in the spyrocompound formation, theses arylidenes were reacted in a tricomponent aza-[3+2+1] annulation, scheme 3 .

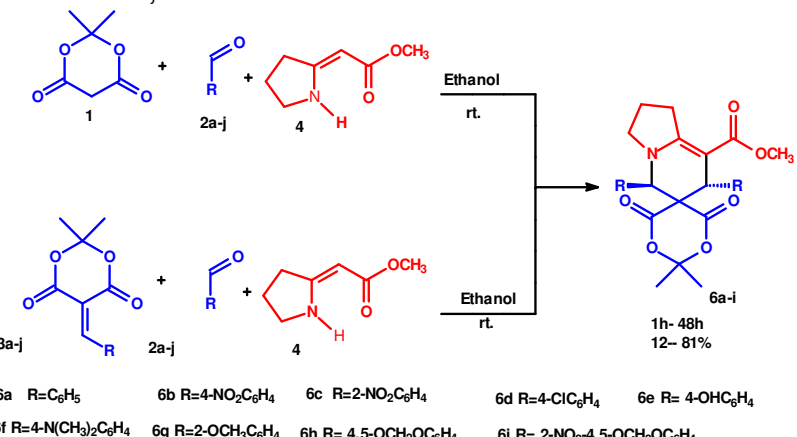

\section{Scheme 3.}

The reaction between cyclic enaminone and 4nitrobenzaldehyde were performed in order to evaluate the mechanism of this transformation. The result was compound $\mathbf{7}$, as a single diastereomer, bearing three consecutives stereogenic centers.

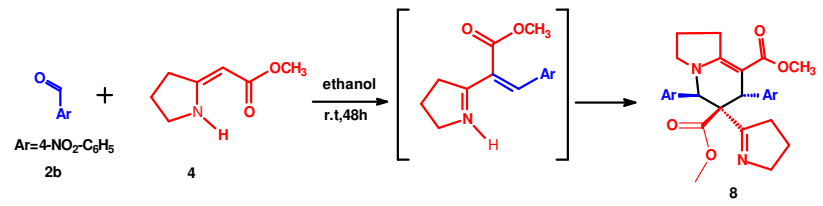

Scheme 5

\section{CONCLUSION}

Meldrum's acid derivatives and enaminones, depending on the conditions used, can react diferently: by a [3+3] bicomponent aza-annulation reaction, by a $[3+2+1]$ trimolecular pathway or by a $[3+1+1+1]$ tetramolecular reaction.

\section{ACKNOWLEDGEMENTS}

To CNPq, FAPESB and CAPES for the financial support.

\section{REFERENCES}

${ }^{1}$ Cunha, S.; Damasceno, F.; Ferrari, J. Tetrahedron Lett. 2007, $48,5795$.

${ }^{2}$ Wang,X.; Zhang, M.; Jiang, H.; Yao,C.; Tu, S. Tetrahedron. 2007, 63, 4439.

${ }^{3}$ Sapi, J.; Laronze, J.; Sigaut, P.; Laronze, M.;Cochard F. Tetrahedron Lett 2004,45,1703-1707

${ }^{4}$ Bigi, F.; Carloni, S.; Ferrari, L.; Maggi, R.;Mazzacani, A.; Sartori, G. Tetrahedron Lett. 2001, 42, 5203-5205.

${ }^{5}$ Ren, Z. J.; Cao, W. G.; Tong, W. Q.; Jing, X. P. Synth. Commun. 2002, 32, 1947. 